\title{
Developmental temperature, body size and male mating success in fruit flies, Drosophila melanogaster (Diptera: Drosophilidae)
}

\author{
SOFIJA PAVKOVIĆ-LUČIĆ and VLADIMIR KEKIĆ \\ University of Belgrade, Faculty of Biology, Institute of Zoology, Studentski trg 16, 11000 Belgrade, Serbia; \\ e-mails: sofija@bio.bg.ac.rs; kekic@eunet.rs
}

Key words. Drosophilidae, developmental temperature, body size, mating success, Drosophila melanogaster

\begin{abstract}
Body size is one of the most investigated traits in studies of sexual selection in fruit flies of the genus Drosophila. In D. melanogaster, size has often been correlated with male mating success, i.e. larger males were more successful in achieving copulations both in laboratory and field conditions. In the present paper, we investigated if male body size is a sexually selected trait in competitive conditions, when full-sibs that developed at two different temperatures $\left(18\right.$ and $\left.25^{\circ} \mathrm{C}\right)$ competed for females. Males developed at a lower temperature were significantly larger than those reared at a higher temperature, but they were not more successful in mating. We conclude that when body size is significantly induced by temperature variability, it is not correlated with male mating success.
\end{abstract}

\section{INTRODUCTION}

Large body size appears to be an advantage for Drosophila fruit flies (Diptera: Drosophilidae) in a broad ecological context. In many species, it is advantageous for both sexes (reviewed by Partridge \& Fowler, 1993) and often correlated with major fitness components (Joshi, 2004), greater flight ability (Gu \& Barker, 1995; Frazier et al., 2008), dispersal ability (Heed \& Mangan, 1986), higher mating success (Partridge et al., 1987a, b; Santos et al., 1988; Vishalakshi \& Singh, 2008), and competitive interactions of different types (Dow \& von Schilcher, 1975; Bangham et al., 2002). Since size is a quantitative phenotypic trait, its variation may be due to complex interplay of genetic, environmental and interactive factors. The highest proportion of genetic variation in this trait is additive (Santos et al., 1988). Very little is known about the genes contributing to differences in body size (De Jong \& Bochdanovits, 2003). However, some biochemical pathways (e.g. those involved in insulin signaling) and gene mutations (e.g. in DHR4, involved in ecdysone signaling) have been identified as those that contribute to adult body size (Mirth \& Riddiford, 2007). Beside genetic factors, different environmental factors (temperature, larval density, quality and quantity of food) also significantly contribute to this phenotypic trait (David et al., 1983).

Temperature is perhaps the most important climatic factor that can explain the geographical distribution of ectothermal insects, including Drosophila. Adult body size varies adaptively among natural populations, i.e. flies that develop at cold temperatures are larger than those developing at warmer temperatures. The phenomenon of climate related adult body size shows clinal variation in Drosophila (Gibert et al., 2004) with larger individuals occurring at higher latitudes and altitudes (McCabe \& Partridge, 1997; Trotta et al., 2010). Drosophila body size also varies seasonally and is inversely proportional to seasonal temperature (Tantawy, 1964; Kari \& Huey, 2000). In laboratory conditions, response of body size to rearing at different temperatures has also been studied: different species that significantly varied in their natural habitats attain larger size when reared at lower temperature (Powell et al., 2010). In addition to morphological traits, rearing temperature may affect some other characteristics, such as physiological (Crill et al., 1996), behavioral (Zamudio et al., 1995), and life history traits (McCabe \& Partridge, 1997).

Body size is one of the most investigated traits in studies of sexual selection in Drosophila. Influence of size on male mating success differs across environments in which studies were conducted (field work or different experimental designs in lab conditions) and across Drosophila species that significantly differ in mating strategies (Markow, 2002). A survey of reported associations between male body size and male mating success in different Drosophila species is presented in Table 1. In most species, larger bodied males were most successful in achieving copulations. There are several arguments for mating advantage of such males. These include that they are physically dominant in aggressive interactions (Dow \& von Schilcher, 1975), have increased courtship vigour (Ewing, 1964), and mate earlier than smaller males (Pavković-Lučić et al., 2009). Also, larger males move faster than smaller rivals, perform courtship steps more quickly and deliver more and louder courtship song (Partridge et al., 1987a). In lek-forming species, larger males are more successful in achieving copulations because they spend more time sexually active at lek sites (Droney, 1992).

In most studies including Drosophila melanogaster Meigen, positive phenotypic correlations between male body size and mating success were recorded, both in the 
TABLE 1. A survey of published associations between male body size and mating success in Drosophila species. Abbreviations: Lab - laboratory research; Field - field study; BS/MS Relation - relation between male body size (BS) and mating success (MS); "+" indicates that larger males were more successful in mating; "-" indicates that mating advantage was associated with small body size; "0" reflects no BS/MS relationship.

\begin{tabular}{|c|c|c|c|}
\hline Species & Conditions & BS/MS Relation & Reference \\
\hline \multirow{2}{*}{ D. ananassae } & Lab & + & Sisodia \& Singh, 2001 \\
\hline & Lab & + & Vishalakshi \& Singh, 2008 \\
\hline D. bipectinata & $\mathrm{Lab}$ & + & Krishna \& Hegde, 2003 \\
\hline \multirow{4}{*}{ D. buzzatii } & Field & + & Santos et al., 1988 \\
\hline & Field & + & Ruiz \& Santos, 1989 \\
\hline & Field & + & Leibowitz et al., 1995 \\
\hline & Lab/Field & + & Santos, 2001 \\
\hline D. grimshawi & $\mathrm{Lab}$ & + & Droney, 1992 \\
\hline \multirow{3}{*}{ D. hydei } & Lab & + & Markow, 1985 \\
\hline & $\mathrm{Lab}$ & + & Pitnick \& Markow, 1994 \\
\hline & Field & 0 & Pavković-Lučić \& Kekić, 2007 \\
\hline D. immigrans & Field & 0 & Pavković-Lučić \& Kekić, 2009 \\
\hline D. littoralis & Field & 0 & Aspi \& Hoikkala, 1995 \\
\hline \multirow{2}{*}{ D. malerkotliana } & Lab & + & Naseerulla \& Hegde, 1992 \\
\hline & $\mathrm{Lab}$ & + & Hegde \& Krishna, 1997 \\
\hline \multirow{10}{*}{ D. melanogaster } & Field & + & Partridge et al., 1987a \\
\hline & $\mathrm{Lab}$ & + & Partridge et al., $1987 \mathrm{~b}$ \\
\hline & Lab & 0 & Wilkinson, 1987 \\
\hline & Lab/Field & $+/+0 *$ & Markow, 1988 \\
\hline & Field & + & Taylor \& Kekić, 1988 \\
\hline & $\mathrm{Lab}$ & + & Pitnick, 1991 \\
\hline & $\mathrm{Lab}$ & + & Markow \& Sawka, 1992 \\
\hline & $\mathrm{Lab}$ & + & Bangham et al., 2002 \\
\hline & Lab & $+/ 0 * *$ & Pavković-Lučić et al., 2009 \\
\hline & Field & + & Pavković-Lučić \& Kekić, 2011 \\
\hline D. mojavensis & Field & + & Markow \& Ricker, 1992 \\
\hline D. montana & Field & $-/ 0 * * *$ & Aspi \& Hoikkala, 1995 \\
\hline D. nasuta & $\mathrm{Lab}$ & + & Krishna \& Hegde, 2003 \\
\hline D. nigrospiracula & Lab/Field & + & Markow, 1988 \\
\hline \multirow{3}{*}{ D. pseudoobscura } & Field & + & Partridge et al., $1987 \mathrm{a}$ \\
\hline & Field & 0 & Markow \& Ricker, 1992 \\
\hline & Field & 0 & Markow et al., 1996 \\
\hline D. rajasekari & $\mathrm{Lab}$ & + & Krishna \& Hegde, 2003 \\
\hline D. silvestris & $\mathrm{Lab}$ & 0 & Boake \& Konigsberg, 1998 \\
\hline \multirow{3}{*}{ D. simulans } & Field & + & Markow \& Ricker, 1992 \\
\hline & Field & 0 & Markow et al., 1996 \\
\hline & $\mathrm{Lab}$ & + & Taylor et al., 2008 \\
\hline \multirow{2}{*}{ D. subobscura } & $\mathrm{Lab}$ & + & Monclús \& Prevosti, 1971 \\
\hline & $\mathrm{Lab}$ & - & Steele \& Partridge, 1988 \\
\hline D. testacea & Field & + & James \& Jaenike, 1992 \\
\hline D. willistoni & $\mathrm{Lab}$ & 0 & Basso Da Silva \& Valente, 2001 \\
\hline
\end{tabular}

* dependent on the breeding site considered; $* *$ sex ratio dependent; $* * *$ during two investigated seasons

laboratory and natural environments (Table 1). However, different experimental conditions may influence size/success relationship. For example, larger males are more successful in matings when males are more abundant than females and when the sex ratio is equal, but not when operational sex ratio is biased toward females (PavkovićLučić et al., 2009). When change in body size is significantly induced by long-term different diets (after maintaining the flies for more than one year on standard cornmeal-agar-sugar-yeast substrate, banana and tomato), larger males are not found to mate faster than smaller ones (Pavković-Lučić \& Kekić, 2010). It seems that the impact of male large size on mating success may vary across experimental treatments and also for different behaviours, including territorial success (Zamudio et al., 1995) and maze-running success (Cohet, 1974). These studies confirmed that size per se is not sexually selected 


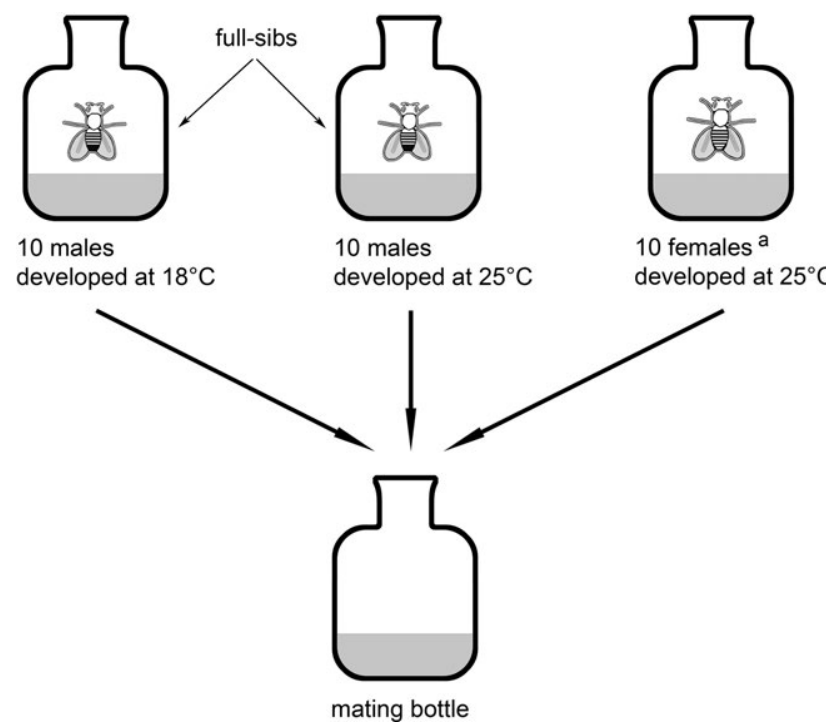

Fig. 1. Scheme of the mating assay (per replica). ${ }^{\text {a }}$ Females were randomly sampled from basic laboratory population.

trait, and, that "bigger is not always better" when other behaviours are also analyzed (Zamudio et al., 1995).

In that respect, we wished to examine whether or not male body size is a sexually selected trait in competitive conditions, when full-sibs developed at two different temperatures $\left(18\right.$ and $\left.25^{\circ} \mathrm{C}\right)$ competed for females. In such conditions, males reared under lower developmental temperature are expected to be larger - but the question is: Will they also be more successful in mating?

\section{MATERIAL AND METHODS}

In order to ensure a precise phenotypic response of body size on developmental temperature, genetically similar males (fullsibs) were used. Other environmental factors known to contribute body size were kept constant if possible (low density of flies, the same quality and quantity of food). Since our question was if the sort of variability involved in determing size was related with adult behavioural phenotype (mating success), factors that may affect mating behavior were also kept uniform (age and mating status - only virgins were used).

\section{Fly strain}

D. melanogaster BGSK strain was used (Obradović et al., 2007). Flies were bred for 67 generations in $250 \mathrm{ml}$ glass bottles under optimal laboratory conditions at $25^{\circ} \mathrm{C}$, relative humidity of about $60 \%$, and $12 \mathrm{~L}: 12 \mathrm{D}$ cycle (light from $8 \mathrm{AM}-8 \mathrm{PM}$ ) and with low larval competition (about 100 individuals per bottle).

\section{Mating assay}

To test male mating success, full-sibs grown at two different temperatures $\left(18^{\circ} \mathrm{C}\right.$ and $\left.25^{\circ} \mathrm{C}\right)$ were used. From $\mathrm{F}_{67}$ generation, 12 males and 12 females were taken and 12 families were formed. Part of the eggs collected from a single pair was put in a climate room at $18^{\circ} \mathrm{C}$, while the other part was reared in the fly room at $25^{\circ} \mathrm{C}$. Two replicates per family were made, i.e. 24 replicates in total.

At $F_{68}$, virgin flies were separated by sex every four hours without anesthesia. Flies from different developmental conditions were then kept at room temperature (about $23-24^{\circ} \mathrm{C}$ ) for 4-8 days, allowing acclimatization to room temperature. Twenty four hours before testing, males whose development

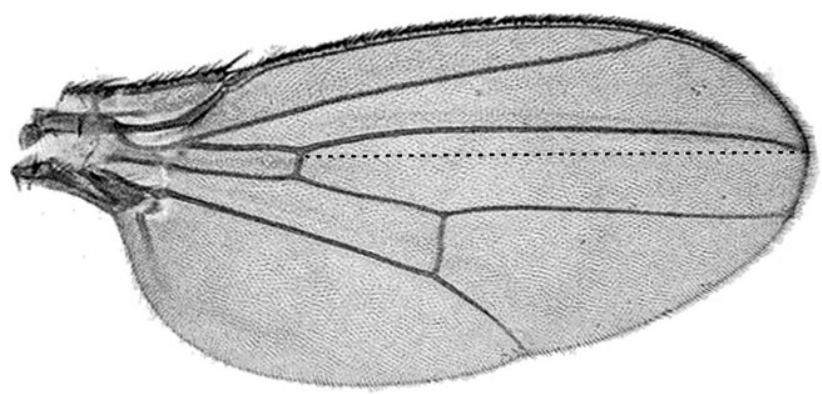

Fig. 2. D. melanogaster wing with marked distance used in approximating body size.

occurred at different temperatures were marked with fluorescent powder (red and green), to make them readily distinguishable under ultraviolet light. Fluorescent dust has been the most commonly used marking method in Drosophila: it has no observable effects on survival (Crumpacker, 1974), does not harm or alter behaviour (McKean \& Nunney, 2008), and can be used as a convenient marker in studies of differential mating success (Terzić et al., 1994). The dusts applied were rotated between replicates.

Females used in the experiment belonged to the same strain, $\mathrm{F}_{68}$; they were virgins, maintained at $25^{\circ} \mathrm{C}$, and of the same age as the males. They were collected from independent vials to the $25^{\circ} \mathrm{C}$ males.

Male mating success was tested during the morning hours at room temperature. Sex ratio was $\mathrm{F}: \mathrm{M}=1: 2$, i.e. males were in competitive conditions. Under these conditions, females have a greater ability to choose mating partners. All males introduced into one mating vial were full-sibs. The following mating assay: 10 males $\left(18^{\circ} \mathrm{C}\right)+10$ males $\left(25^{\circ} \mathrm{C}\right)+10$ females $\left(25^{\circ} \mathrm{C}\right)$ was performed in 24 replicates (Fig. 1).

Twenty three replicates were made as descibed above, while in the last replica (because of the limited number of individuals), 6 females were mated with 6 males originating from two different developmental temperatures. Each individual test (replicate) lasted $60 \mathrm{~min}$. Within a single test, males were of the same age, thus avoiding the effect of age on mating performance.

After copulation occured, males were identified under a UV lamp. Mating pairs as well as non-mates (labelled as "unsuccessful") were then scored for size. In Drosophila, wing length is commonly used as a measure of body size. It was scored as the length of the third longitudinal vein (the distance from the wing tip to its intersection with the anterior crossvein; Partridge et al., 1987a) (Fig. 2).

To determine the presence/absence of significant difference between the mean body sizes, a $t$-test was used to compare mean body sizes between males reared at two developmental temperatures, as well as between mated and unmated males within each developmental temperature. The numerical data used in comparing average wing lengths were obtained by measuring the right wing under binocular microscope fitted with an ocular scale and were expressed in millimeters $(\mathrm{mm})$. Difference in the number of copulations achieved by males whose development occurred at different temperatures was tested by Chi square testing, calculated on the basis of $1: 1$ null hypothesis.

\section{RESULTS}

Two developmental temperatures resulted in expected phenotypic response in size, i.e. significantly larger males were reared under lower temperature. The mean wing 


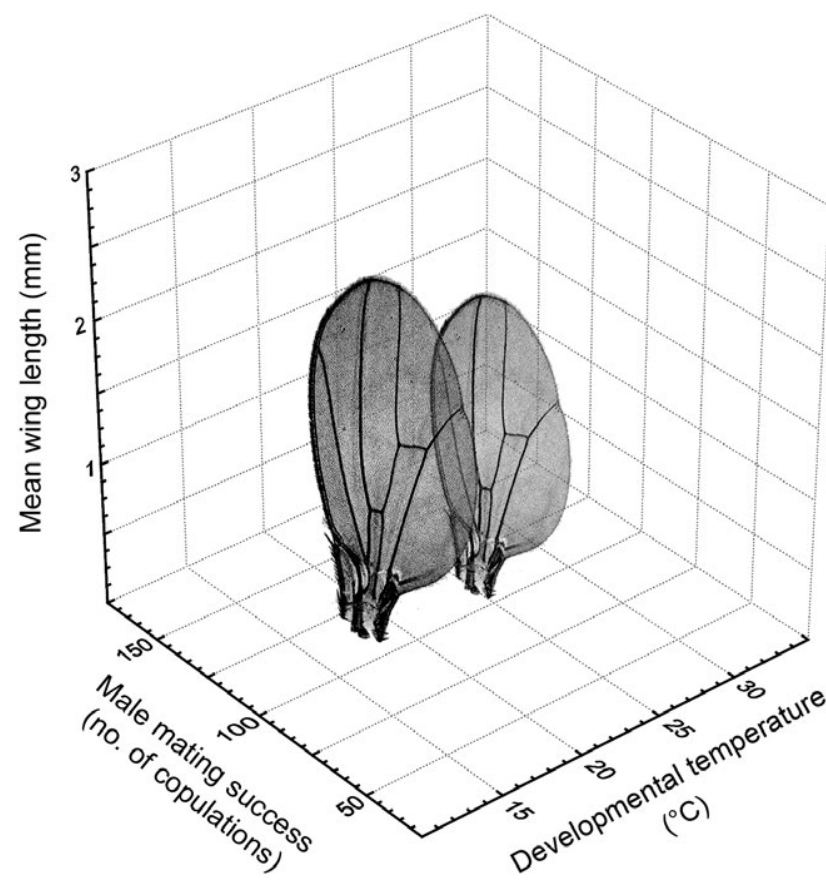

Fig. 3. Male mating success (scored as number of copulations) in males of different sizes, developed at two different temperatures $\left(18\right.$ and $\left.25^{\circ} \mathrm{C}\right)$.

length $(\bar{x} \pm \mathrm{SE})$ of males developed at $18^{\circ} \mathrm{C}(\mathrm{N}=107)$ was $1.6049 \pm 0.0039 \mathrm{~mm}$ and the mean wing length $(\bar{x} \pm$ $\mathrm{SE})$ of males developed at $25^{\circ} \mathrm{C}(\mathrm{N}=94)$ was $1.4450 \pm$ $0.0040 \mathrm{~mm}$. This difference, estimated by $t$-testing, was statistically significant $(t=28.576, \mathrm{df}=199, P<0.0001)$.

Mating success of males developed at two different temperatures was tested by Chi-square testing, under the assumption, as aforementioned, that both male groups would be equally succesful in mating. No significant difference in the number of copulations (which is a measure of success in mating) was recorded between males which differed in size, substantially caused by different temperatures during development. Larger males (reared at $18^{\circ} \mathrm{C}$ ) achieved 112 copulations, while smaller ones (reared at $25^{\circ} \mathrm{C}$ ) took part in 106 copulations. The Chi square test was non-significant $\left(\chi^{2}=0.16, \mathrm{df}=1, P>0.05\right)$, showing that both male groups had equal mating success.

When combined results of previous statistics are presented in the three-dimensional coordinate system, difference in mean body sizes between males reared at two temperatures was observed, although no significant separation between the two groups of males was recorded when the number of copulations was compared (Fig. 3).

Furthermore, within each temperature, significant difference between mean body sizes of copulating and noncopulating males was not observed. Mated and unmated males reared at $18^{\circ} \mathrm{C}$ did not differ in average body size; the same was observed for males developed at $25^{\circ} \mathrm{C}$ (Table 2).

\section{DISCUSSION AND CONCLUSIONS}

Temperature is one of the most important environmental factors affecting a diverse array of morphological, physiological and behavioral traits in Drosophila, as well as their distribution and abundance (Gibbs et al., 1998). The effect of developmental temperature on body size is an example of phenotypic plasticity, which includes the ability of flies to alter their morphology, physiology or development as a result of changes in the environment (Sisodia \& Singh, 2002). In the present study, we tested the effect of developmental temperature on Drosophila adult male body size and mating success. We expected, according to numerous literature data, that males reared at a lower temperature would be larger than those reared at higher temperature (David et al., 1983; Gibert et al., 2004). Our results confirmed a significant difference in size between males from different developmental temperatures. Furthermore, in our experiments, males that experienced different thermal regimes during pre-adult development competed for females. In those conditions, according to the "size-advantage hypothesis" (Huey et al., 1995), males that develop at $18^{\circ} \mathrm{C}$ should benefit in mating success due to their larger size. This, however, was found not the case according to our trials. Size per se did not contribute to higher mating success of larger bodied males, since they were no more successful in mating than their smaller rivals. Similar results were obtained when territorial behavior of this species was investigated: adults reared at $25^{\circ} \mathrm{C}$ were smaller, but equally successful in defending the territory as males reared at a lower temperature $\left(18^{\circ} \mathrm{C}\right)$ (Zamudio et al., 1995).

In our experiments, males developed at $25^{\circ} \mathrm{C}$, although smaller than those reared at $18^{\circ} \mathrm{C}$, possessed enough vigour to copulate with females in almost the same proportion as larger males. As $25^{\circ} \mathrm{C}$ represents an optimal developmental temperature for the species (Huey et al., 1995), it is possible that optimal growth condition may affect also some other traits included in sexual selection (physiological or behavioral properties). It has been previously observed (reviewed by Zamudio et al., 1995) that flies reared at optimal temperature have better performance of some behavioral traits, as well as higher fitness. In this sense, smaller males may be equally successful as larger, since development at $25^{\circ} \mathrm{C}$ might be physiologically more advantageous than development at $18^{\circ} \mathrm{C}$, such that smaller males might be sufficiently vigorous in courting and compensate, in some way, for being small

TABLE 2. Mean wing length $(\bar{x} \pm \mathrm{SE})$ of mated and unmated males within each developmental temperature $\left(18\right.$ and $\left.25^{\circ} \mathrm{C}\right) ; t$-test.

\begin{tabular}{cccccccc}
\hline $\begin{array}{c}\text { Developmental } \\
\text { temperature }\left({ }^{\circ} \mathrm{C}\right)\end{array}$ & $\begin{array}{c}\text { Mated males } \\
(N)\end{array}$ & $\bar{x} \pm \mathrm{SE}(\mathrm{mm})$ & $\begin{array}{c}\text { Unmated } \\
\text { males }(N)\end{array}$ & $\bar{x} \pm \mathrm{SE}(\mathrm{mm})$ & $t$-test & d.f. & $P$ \\
\hline 18 & 107 & $1.6049 \pm 0.0039$ & 96 & $1.6080 \pm 0.0048$ & 0.514 & 201 & 0.608 \\
25 & 94 & $1.4450 \pm 0.0040$ & 95 & $1.4420 \pm 0.0039$ & 0.537 & 187 & 0.592 \\
\hline
\end{tabular}


(Zamudio et al., 1995). Alternatively, it is possible that development at $18^{\circ} \mathrm{C}$ (within D. melanogaster natural thermal range; Jones et al., 1987) was at least partially stressful, since flies were adapted to higher developmental temperature (they were reared for more than two years in optimal laboratory conditions before being used in the experiment). The reaction to lower developmental temperature may further be reflected on examined behavioral phenotype (mating success) through changes in male physiological state.

It was previously noted (Joshi, 2004) that the causes of the size variation can greatly affect how size is correlated with male and female fitness components in Drosophila. For example, when the variation in body size was induced by variability in the larval density, body size was found to be positively correlated with male mating success in $D$. buzzatii Patterson \& Wheeler (Santos, 1996). However, when body size was induced by temperature variability, it seems not to be correlated with territorial (Zamudio et al., 1995) and mating success (this study). Furthermore, developmental temperature may influence some other traits involved in complex mating behavior not examined here. Olfactory profiles (cuticular hydrocarbons) involved in mate choice in some Drosophila species may be affected by developmental temperatures (Markow \& Toolson, 1990); for example, in D. mojavensis (Patterson \& Crow), mean hydrocarbon chain length increased at higher temperatures (Gibbs et al., 1998).

Our observations on D. melanogaster do not necessarily contradict previous reports on this species, when, in a number of studies, larger males had mating advantage. Rather, and more subtly, our results imply that a significant contribution of one environmental factor (temperature) on size variability does not influence mating success in the expected way. This implies that size-dependent sexual selection (mate competition and/or mate choice) may be related to factors involved in trait determination. In future studies, similar investigations could be conducted such that males are kept "genetically constant", whilst varying the other environmental factors known to induce differences in adult body size. It is also possible that sexual selection depends more on the genetic contribution to this phenotypic trait, which is possible to test for by varying the genetic background of the stocks in a "constant environment". In addition, large body size is certainly not the only trait that determines male mating success. It is also influenced by a wide range of genetic variables that determine, for example, eye colour, which is unrelated to size, as well as by age and mating experience (see Markow, 1988 for a review). Quality and quantity of stimuli delivered by male during courtship (visual, acoustic, olfactory, tactile, gustatory; see Greenspan \& Ferveur, 2000) also have significant impact on their success in mating.

Our results also revealed no difference in average body size between mated and unmated males developed within the same temperature, although the sample was relatively large. It is expected that, among flies reared at the same temperature, mated males would be greater than unmated ones. However, this pattern was not observed. The most likely explanation is that there was little genetic or environmental variance in body size or fitness within each thermal regime. Probably the most important reason for such result, in our view, is that the genetic variability between the examined males was greatly reduced. Therefore, what distinguishes this simple experiment is the low genetic variability between mated and unmated males. Otherwise, heritabilities of traits related to body size have previously been estimated in different Drosophila species to range from $10 \%$ to $60 \%$, or even more (Coyne \& Beecham, 1987; Mousseau \& Roff, 1987; Stanić \& Marinković, 1990; Sgro \& Hoffmann, 1998; Orengo \& Prevosti, 1999). Estimation of heritability, by definition, is only valid for the population and circumstances in which it is examined (Orengo \& Prevosti, 1999). In most studies, heritability estimates for body size-related traits were lower in nature than in the laboratory, largely due to the higher phenotypic variance in nature (Coyne \& Beecham, 1987; Prout \& Barker, 1989; Sgro \& Hoffmann, 1998; Orengo \& Prevosti, 1999).

Lastly, not only male body size, but female preference for this particular trait may also be environmentally plastic. Females may prefer different male traits in cold than in warm environments, i.e. sexual selection of males may be divergent across environments because males will be selected to produce phenotype preferred by females in that environment (Dolgin et al., 2006). This is most certainly worth investigating in future research, since here we have not tested females reared at $18^{\circ} \mathrm{C}$, neither was the testing performed at a lower temperature. In this way, a test of the "acclimation advantage hypothesis", (Huey et al., 1995) could also be provided, i.e. if development at one temperature enhances adult behavioral performance (e.g. mating success) at that temperature.

ACKNOWLEDGEMENTS. This work was supported by the Serbian Ministry of Education and Science (Grant 173012). The authors thank the anonymous reviewers for their helpful comments and suggestions during the review process.

\section{REFERENCES}

Aspi J. \& HoikKala A. 1995: Male mating success and survival in the field with respect to size and courtship song characters in Drosophila littoralis and D. montana. - J. Insect Behav. 8: 67-87.

Bangham J., Chapman T. \& Partridge L. 2002: Effects of body size, accessory gland and testis size on pre-and postcopulatory success in Drosophila melanogaster. - Anim. Behav. 64: 915-921.

Basso Da Silva L. \& Valente V.L.S. 2001: Body size and mating success in Drosophila willistoni are uncorrelated under laboratory conditions. - J. Genet. 80: 77-81.

BoAke C.R.B. \& Konigsberg L. 1998: Inheritance of male courtship behavior, aggressive success, and body size in Drosophila silvestris. - Evolution 52: 1487-1492.

COHET Y. 1974: Réduction de l'activité locomotorice d'adults de Drosophila melanogaster provoquée par développment à basse témperature. - Rev. Comp. Anim. 8: 121-125.

Coyne J.A. \& Beecham E. 1987: Heritability of two morphological characters within and among natural populations of Drosophila melanogaster. - Genetics 117: 727-737. 
Crill W.D., Huey R.B. \& Gilchrist G.W. 1996: Within- and between-generation effects of temperature on the morphology and physiology of Drosophila melanogaster. - Evolution 50: $1205-1218$.

Crumpacker D.W. 1974: The use of micronized fluorescent dust to mark adult Drosophila pseudoobscura. - Am. Midland Nat. 91: 119-129.

David J.R., Allemand R., Van Herewege J. \& Cohet Y. 1983: Ecophysiology: abiotic factors. In Ashburner M., Carson H.L. \& Thompson J.N. (eds): The Genetics and Biology of Drosophila. Vol. 3d. Academic Press, London, pp. 105-170.

De Jong G. \& Bochdanovits Z. 2003: Latitudinal clines in Drosophila melanogaster: body size, allozyme frequencies, inversion frequencies, and the insulin-signalling pathway. $-J$. Genet. 82: 207-223.

Dolgin E.S., Whitlock M.C. \& Agrawal A.F. 2006: Male Drosophila melanogaster have higher mating success when adapted to thermal environment. - J. Evol. Biol. 19: 1894-1900.

Dow M.A. \& von SCHILCHER F. 1975: Aggression and mating success in Drosophila melanogaster. - Nature 254: 511-512.

Droney D. 1992: Sexual selection in a lekking Hawaiian Drosophila: the roles of male competition and female choice in male mating success. Anim. Behav. 44: 1007-1020.

EwING A.W. 1964: The influence of wing area on the courtship behaviour of Drosophila melanogaster. - Anim. Behav. 12: 316-320.

Frazier M.R., Harrison J.F., Kirkton S.D. \& Roberts S.P. 2008: Cold rearing improves cold-flight performance in Drosophila via changes in wing morphology. - J. Exp. Biol. 211: 2116-2122.

GibBs A.G., Louie A.K. \& Ayala J.A. 1998: Effects of temperature on cuticular lipids and water balance in a desert Drosophila: is thermal acclimation beneficial? -J. Exp. Biol. 201: $71-80$.

Gibert P., Capy P., Imasheva A., Moreteau B., Morin J.P., Petavy G. \& David J.R. 2004: Comparative analysis of morphological traits among Drosophila melanogaster and Drosophila simulans: genetic variability, clines and phenotypic plasticity. - Genetica 120: 165-179.

Greenspan R.J. \& Ferveur J.F. 2000: Courtship in Drosophila - Annu. Rev. Genet. 34: 205-232.

GU H. \& BARKER J.S.F. 1995: Genetic and phenotypic variation for flight ability in the cactophilic Drosophila species, D. aldrichi and D. buzzatii. - Entomol. Exp. Appl. 76: 25-35.

Heed W.B. \& Mangan R.L. 1986: Community ecology in Sonoran desert Drosophila. In Ashburner M., Carson H.L. \& Thompson J.N. (eds): The Genetics and Biology of Drosophila. Academic Press, New York, pp. 311-345.

Hegde S.N. \& Krishna S.N. 1997: Size-assortative mating in Drosophila malerkotliana. - Anim. Behav. 54: 419-426.

Huey R.B., Wakefield T., Crill W.D. \& Gilchrist G.W. 1995: Within- and between-generation effects of temperature on early fecundity of Drosophila melanogaster. - Heredity 74: $216-223$.

JAMES A. \& JAENIKE J. 1992: Determinants of male mating success in Drosophila testacea. - Anim. Behav. 44: 168-170.

Jones J.S., Coyne J.A. \& Partridge L. 1987: Estimation of the thermal niche of Drosophila melanogaster using a temperature-sensitive mutation. - Am. Nat. 130: 83-90.

Joshi A. 2004: Are bigger flies always better: the role of genes and environment. - J. Genet. 83: 13-15.

Kari J.S. \& HueY R.B. 2000: Size and seasonal temperature in free-ranging Drosophila subobscura. - J. Thermal Biol. 25: $267-272$.
Krishna M.S. \& Hegde S.N. 2003: Influence of body size in mating success in three sympatric species of Drosophila. Ital. J. Zool. 70: 47-52.

Leibowitz A., Santos M. \& Fontdevila A. 1995: Heritability and selection on body size in a natural population of Drosophila buzzatii. - Genetics 141: 181-189.

MARKOW T.A. 1985: A comparative investigation of the mating system of Drosophila hydei. - Anim. Behav. 33: 775-781.

MARKOw T.A. 1988: Reproductive behavior of Drosophila in the laboratory and in the field. - J. Comp. Physiol. 102: 169-174.

MARKow T.A. 2002: Perspective: female remating, operational sex-ratio, and the arena of sexual selection in Drosophila species. - Evolution 56: 1725-1734.

Markow T.A. \& Ricker J.P. 1992: Male size, developmental stability and mating success in natural populations of three Drosophila species. - Heredity 69: 122-127.

MARKow T.A. \& SAWKA S. 1992: Dynamics of mating success in experimental groups of Drosophila melanogaster (Diptera: Drosophilidae). - J. Insect Behav. 5: 375-383.

MARKow T.A. \& ToOLsON E.C. 1990: Temperature effects on epicuticular hydrocarbons and sexual isolation in Drosophila mojavensis. In Barker J.S.F., Starmer W.T. \& MacUntyre R.J. (eds): Ecological and Evolutionary Genetics of Drosophila. Plenum Press, New York, pp. 315-331.

Markow T.A., Bustoz D. \& Pitnick S. 1996: Sexual selection and a secondary sexual character in two Drosophila species. - Anim. Behav. 52: 759-766.

McCABe J. \& PARTRIDGe L. 1997: An interaction between environmental temperature and genetic variation for body size for the fitness of adult female Drosophila melanogaster. - Evolution 51: 1164-1174.

McKean K.A. \& Nunney L. 2008: Sexual selection and immune function in Drosophila melanogaster. - Evolution 62: 386-400.

Mirth C.K. \& Riddiford L.M. 2007: Size assessment and growth control: how adult size is determined in insects. BioEssays 29: 344-355.

Monclús M. \& Prevosti A. 1971: The relationship between mating speed and wing length in Drosophila subobscura. Evolution 25: 214-217.

Mousseau T.A. \& RofF D.A. 1987: Natural selection and the heritability of fitness components. - Heredity 59: 181-197.

Naseerulla M.K. \& Hegde S.N. 1992: Relationships between wing size and mating speed in Drosophila malerkotliana. Boll. Zool. 59: 367-370.

Obradović T., Pavković-Lučić S. \& Kekić V. 2007: Growth temperature, duration of development, preadult viability, and body size in Drosophila melanogaster. - Dros. Inf. Serv. 90: 109-111.

Orengo D.J. \& Prevosti A. 1999: Wing-size heritability in a natural population of Drosophila subobscura. - Heredity 82: 100-106.

Partridge L. \& Fowler K. 1993: Responses and correlated responses to artificial selection on thorax length in Drosophila melanogaster. - Evolution 47: 213-226.

Partridge L., Hoffmann A. \& Jones J.S. 1987a: Male size and mating success in Drosophila melanogaster and Drosophila pseudoobscura under field conditions. - Anim. Behav. 35: 468-476.

Partridge L., Ewing A. \& Chandler A. 1987b: Male size and mating success in Drosophila melanogaster: the roles of male and female behaviour. - Anim. Behav. 35: 555-562. 
PAvković-Lučić S. \& Kekić V. 2007: Is body size a sexually selected trait in Drosophila hydei males? - Arch. Biol. Sci. 59(2): 21P-22P.

Pavković-Lučić S. \& Kerić V. 2009: Body size and mating success in Drosophila immigrans: a field study. - Arch. Biol. Sci. 61(4): 7P-8P.

PAvković-Lučić S. \& KeKić V. 2010: Nutrition quality, body size and two components of mating behavior in Drosophila melanogaster. - Folia Biol. (Kraków) 58: 113-117.

Pavković-Lučić S. \& KeKić V. 2011: Are larger and/or more symmetrical Drosophila melanogaster (Diptera, Drosophilidae) males more successful in mating in nature? - Rev. Bras. Entomol. 55: 583-588.

Pavković-Lučić S., Kerić V. \& Čvoro A. 2009: Larger male mating advantage depends on sex ratio in Drosophila melanogaster. - Ethol. Ecol. Evol. 21: 155-160.

PITNICK S. 1991: Male size influences mate fecundity and remating interval in Drosophila melanogaster. - Anim. Behav. 41: 735-745.

Pitnick S. \& Markow T.A. 1994: Large-male advantages associated with costs of sperm production in Drosophila hydei a species with giant sperm. - Proc. Nat. Acad. Sci. U.S.A. 91: 9277-9281.

Powell A.M., Davis M. \& Powell J.R. 2010: Phenotypic plasticity across $50 \mathrm{MY}$ of evolution: Drosophila wing size and temperature. - J. Insect Physiol. 56: 380-382.

Prout T. \& Barker J.S.F. 1989: Ecological aspects of the heritability of body size in Drosophila buzzatii. - Genetics $\mathbf{1 2 3}$ : 803-813.

Ruiz A. \& SAntos M. 1989: Mating probability, body size, and inversion polymorphism in a colonizing population of Drosophila buzzatii. In Fontdevila A. (ed.): Evolutionary Biology of Transient Unstable Populations. Springer, Berlin, Heidelberg, pp. 96-113.

SANTOS M. 1996: Apparent directional selection of body size in Drosophila buzzatii: larval crowding and male mating success. - Evolution 50: 2530-2535.

SANTOS M. 2001: Fluctuating asymmetry is nongenetically related to mating success in Drosophila buzzatii. - Evolution 55: 2248-2256.

Santos M., Ruiz A., Barbadilla A., Quezada-Diaz J.E., Hasson E. \& Fontdevila A. 1988: The evolutionary history of Drosophila buzzatii. XIV. Larger flies mate more often in nature. Heredity 61: 255-262.
Sgro C.M. \& Hoffmann A.A. 1998: Heritable variation for fecundity in field-collected Drosophila melanogaster and their offspring reared under different environmental temperatures. - Evolution 52: 134-143.

Sisodia S. \& Singh B.N. 2001: Mating success and morphometric traits in Drosophila ananassae. - Curr. Sci. 80: 1444-1447.

Sisodia S. \& Singh B.N. 2002: Effect of temperature on longevity and productivity in Drosophila ananassae: evidence for adaptive plasticity and trade-off between longevity and productivity. - Genetica 114: 95-102.

Stanić S. \& MarinKović D. 1990: Intrinsic and acquired in reproductive behavior of Drosophila. - Arch. Biol. Sci. 42: 7P-8P.

Steele R.H. \& Partridge L. 1988: A courtship advantage for small males in Drosophila subobscura. - Anim. Behav. 36: 1190-1197.

TANTAWy A.O. 1964: Studies on natural populations of Drosophila. III. Morphological and genetic differences of wing length in Drosophila melanogaster and D. simulans in relation to season. - Evolution 18: 560-570.

TAYlor C.E. \& KeKIĆ V. 1988: Sexual selection in a natural population of Drosophila melanogaster. - Evolution 42: 197-199.

Taylor M.L., Wedell N. \& Hosken D.J. 2008: Sexual selection and female fitness in Drosophila simulans. - Behav. Ecol. Sociobiol. 62: 721-728.

Terzic T., Andjelkovic M. \& Stamenkovic-Radak M. 1994: Effect of fluorescent dust, as a marker, on the frequency of mating in Drosophila melanogaster. - Dros. Inf. Serv. $\mathbf{7 5}$ : 164-165.

Trotta V., Pertoldi C., Rudoy A., Manenti T., Cavicchi S. \& Guerra D. 2010: Thermal plasticity of wing size and shape in Drosophila melanogaster, Drosophila simulans and their hybrids. - Clim. Res. 43: 71-79.

Vishalakshi C. \& Singh B.N. 2008: Mating success is not correlated with fluctuating asymmetry in Drosophila ananassae. Curr. Sci. 94: 375-381.

WILKINSON G. S. 1987: Equilibrium analysis of sexual selection in Drosophila melanogaster. - Evolution 41: 11-21.

Zamudio K.R., Huey R.B. \& CRill W.D. 1995: Bigger isn't always better: body size, developmental and parental temperature and male territorial success in Drosophila melanogaster. - Anim. Behav. 49: 671-677.

Received November 29, 2011; revised and accepted August 6, 2012 